\title{
Changes in the crystalline degree in neutron irradiated EPDM viewed through infrared spectroscopy and inelastic neutron scattering
}

\author{
Osvaldo Agustín Lambri ${ }^{1}$, Enrique David Victor Giordano ${ }^{1,2}$, Federico Guillermo Bonifacich ${ }^{1}$, \\ Mónica Jiménez-Ruiz ${ }^{3}$, Mariel Antonella Lambri ${ }^{1}$, Fernando Ariel Sánchez ${ }^{4}$, \\ José Ignacio Pérez-Landazábal ${ }^{5}$, José Ángel García ${ }^{6}$, Carlos Eugenio Boschetti ${ }^{2}$, \\ Vicente Recarte ${ }^{5}$, Fernando Plazaola ${ }^{6}$, Pablo Ernesto Salvatori ${ }^{2}$
}

\author{
${ }^{1}$ CONICET - UNR, Laboratorio de Materiales, Escuela de Ingeniería Eléctrica, Centro de Tecnología e Investigación \\ Eléctrica, Facultad de Ciencias Exactas, Ingeniería y Agrimensura, Av. Pellegrini 250, CP: 2000, Rosario, Santa Fé, \\ Argentina. \\ e-mail: olambri@fceia.unr.edu.ar; david_giordano@outlook.com; bonifaci@fceia.unr.edu.ar; mariel.lambri@gmail.com \\ ${ }^{2}$ CONICET - IPROBYQ, Área de Tecnología Química, Facultad de Ciencias Bioquímicas y Farmacéuticas, Suipacha \\ 531, CP: 2000, Rosario, Santa Fé, Argentina. \\ e-mail: cboschet@ fbioyf.unr.edu.ar \\ ${ }^{3}$ Institut Laue Langevin (ILL), 71 Av. des Martyrs, B.P. 156, 38042 Grenoble Cedex 9, Grenoble, Isère, France. \\ e-mail: jimenez@ill.fr \\ ${ }^{4}$ División Física de Reactores Avanzados, Reactor Nuclear RA 6, Centro Atómico Bariloche, CNEA, Avda. Bustillo km \\ 9.500, R8402AGP San Carlos de Bariloche, Bariloche, Río Negro, Argentina. \\ e-mail: sanchezf@cab.cnea.gov.ar \\ ${ }^{5}$ Departamento de Física, Universidad Pública de Navarra, Campus de Arrosadía 31006, Pamplona, Navarra, Spain. \\ e-mail: ipzlanda@unavarra.es; recarte@unavarra.es \\ ${ }^{6}$ Facultad de Ciencias y Tecnología, Universidad del País Vasco. Apdo. 644, 48080 Bilbao, Biscaia, Spain. \\ e-mail: joseangel.garcia@ehu.es; fernando.plazaola@ehu.eus
}

\begin{abstract}
The changes in the degree of crystallinity in commercial Ethylene Propylene Diene rubber-type M (EPDM) irradiated with neutrons at different doses has been studied by means of inelastic neutron scattering and infrared absorption spectroscopy experiments. EPDM samples were taken from the housing of non-ceramic electrical insulators which are used in outdoor transmission lines of $66 \mathrm{kV}$. Inelastic neutron scattering spectra were recorded at $5 \mathrm{~K}$ with an accessible energy-transfer range between $180-3500 \mathrm{~cm}^{-1}$. Infrared studies were performed at room temperature with an energy transfer between $4000-400 \mathrm{~cm}^{-1}$. Controlled neutron irradiation allows to obtain different volume fraction and size of crystalline zones in EPDM. The obtained results are discussed and correlated with studies of differential scanning calorimetry, dynamic mechanical analysis and positron annihilation lifetime spectroscopy from where the changes in crystallinity in EPDM were indirectly studied. Inelastic neutron scattering studies were not appropriate for determining the changes in the crystallinity degree in neutron irradiated commercial EPDM. In contrast, from infrared absorption spectroscopy the changes in crystallinity could be determined successfully.
\end{abstract}

Keywords: EPDM, inelastic neutron scattering, infrared absorption spectroscopy, crystallinity, ageing.

\section{INTRODUCTION}

Composite polymeric insulators are widely used for applications at high voltages in both the distribution and transmission voltage ranges due to their substantial advantage compared to inorganic insulators which have primarily been porcelain and glass. Their major advantages are their low surface energy, light weight, a higher mechanical strength to weight ratio, easy installation and the reduction of maintenance cost, among others; see for more details [1]. However, the environmental effects lead to a critical aging of the polymer producing degradation in its physical, mechanical and electrical properties [1-3]. For instance, it has been shown that the outdoor ageing leads to a decrease in the crystalline volume fraction in EPDM (ethylene- 
propylene-diene M-class rubber) [3]. More recently, it has been shown the closely relation between the behaviour of the dielectric strength and the crystalline degree in EPDM [2]. Therefore, the tools for determining the crystalline degree in EPDM have high interest in the field of the power electrical engineering. Nevertheless, the determination of the crystalline changes in EPDM, during outdoor service or in accelerated ageing at the laboratory, by means of direct techniques as infrared absorption spectroscopy or $\mathrm{X}$-ray diffraction is often very difficult or an impossible work [2,4-6]. In fact, the small volume fraction of crystallites in EPDM and its small changes both in volume fraction and size make a difficult task for the experimental work [2,4-8].

The aim of the present work is to attempt of resolving this issue by means of exploring the responses of inelastic neutron scattering (INS) and infrared absorption spectroscopy (IR) techniques applied to controlled neutron irradiated commercial EPDM. In fact, controlled neutron irradiation is an excellent aging tool in order to promoted different volume fraction and size of crystalline zones [5,6,9,10]. Results are discussed and correlated with studies of differential scanning calorimetry (DSC), dynamic mechanical analysis (DMA) and positron annihilation lifetime spectroscopy (PALS) from where, the changes in crystallinity in EPDM were indirectly studied.

\section{EXPERIMENTAL}

\subsection{Samples}

Samples were taken from commercial EPDM used as housing of non-ceramic electrical insulators (Avator of Sitece Electrical Industries, Buenos Aires, Argentina), which are employed in outdoor transmission lines of $66 \mathrm{kV}$. EPDM composition was determined by means of IR spectroscopy, following directions of ASTM D 3900 standard [11]. The nominal molar composition of the rubber was $65 \%$ ethylene $-32 \%$ propylene and $3 \%$ ethylidene-norborene. EPDM used in the present work was reinforced with ceramic particles of Bayerite (alumina-trihydrate, ATH) in a proportion of $44 \mathrm{wt} \%$, as it is usual for electrical applications in order to improve the flashover resistance [1].

\subsection{Neutron irradiation}

Neutron irradiations were performed at the RA-6 nuclear reactor of the National Atomic Energy Commission of Argentina, which was operated at $400 \mathrm{~kW}$. All samples were irradiated with bismuth and cadmium filters at room temperature in air. The thermal and fast neutron fluxes were $1.7 \times 10^{8} \mathrm{n} / \mathrm{cm}^{2} \mathrm{~s}$ and $5.5 \times 10^{8} \mathrm{n} / \mathrm{cm}^{2} \mathrm{~s}$, respectively. The irradiation doses for the studied samples were 82, 415, 830, 4150 and $8300 \mathrm{~Gy}$. In addition the charge with Bayerite in the EPDM gave rise to an additional irradiation process through $\beta$ particles. In all the irradiated samples the activity was smaller than $5.6 \times 10^{4} \mathrm{~Bq}$. By considering the whole reactions of the neutron irradiation process over the Bayerite [12], the following $\beta$ doses corresponding to the neutron ones can be obtained (less than) 3, 6, 15 and 30 Gy, respectively [6].

\subsection{Measurements}

Neutron vibrational spectra were recorded at $\mathrm{T}=5 \mathrm{~K}$ on the IN1-Lagrange hot neutron spectrometer (Lagrange). The incident energy on this spectrometer is varied stepwise, and it is selected by Bragg scattering from different monochromators (two $\mathrm{Cu}$ and one $\mathrm{Si}$ ). In this work, the incident frequency range $216-3500$ $\mathrm{cm}^{-1}$ was covered with the double-focused $\mathrm{Cu}(220)$ reflexion, giving a high flux but a moderate instrumental resolution of $\sim 3 \%\left(\Delta \mathrm{E}_{\mathrm{i}} / \mathrm{E}_{\mathrm{i}}\right)$. The neutrons scattered by the sample are focused on a single counter of $\mathrm{He}^{3}$ by a reflecting surface built around the vertical sample-detector axis from pyrolitic graphite crystals set to reflect neutrons at a final energy of $4.5 \mathrm{meV}$. The cooled Be filter is installed after the sample to remove higherorder harmonics in the analyzer reflections. In such experimental conditions the accessible energy-transfer range was $180-3500 \mathrm{~cm}^{-1}$. The spectra were recorded at $5 \mathrm{~K}$, to decrease the mean-square amplitude of the atoms, $\left\langle\mathrm{u}^{2}\right\rangle$, and thus to sharpen the bands. Data are corrected from the multiple reflections of the monochromator and empty cell.

IR studies were carried out in a Shimadzu Prestige 21, FTIR spectrometer, with an attenuated total reflectance (ATR) accessory. 40 scans per spectrum, in the wavenumber range of $4000-400 \mathrm{~cm}^{-1}$ with a resolution of $4 \mathrm{~cm}^{-1}$, were used for each studied sample.

DSC measurements were performed in a Perkin-Elmer Jade DSC equipment with aluminium crucibles at a heating rate of $10 \mathrm{~K} / \mathrm{min}$. Measurements were performed under helium at atmospheric pressure. The temperature explored interval was from $173 \mathrm{~K}$ up to $368 \mathrm{~K}$. 
PALS measurements were performed at $300 \mathrm{~K}$ by a conventional fast-fast timing coincidence system with a resolution (full width at half maximum) of $240 \mathrm{ps}$. As positron source a ${ }^{22} \mathrm{NaCl}$ source of about $15 \mu \mathrm{Ci}$ evaporated onto a thin Kapton foil was used. The measuring time for all the neutron irradiated samples was similar. All lifetime spectra were analyzed in three components after subtracting the source contribution. The LT_92_3 program [13] to fit the spectra with a continuous distribution of positron lifetimes for the long lifetime $\tau_{3}$ was used. In the present work, we are interested in the evolution of the average of the free volume; so, we have particularly analyzed the parameters of the long component, lifetime and intensity, which are related to the free volume present in the sample. The mean free volume hole size, $\mathrm{V}_{\mathrm{f}}$, assuming a spherical form for the holes, may be estimated by means of the following equation:

$$
V_{f}=\left(\frac{4 \pi}{3}\right) R^{3}
$$

where the free-volume radius, $\mathrm{R}$, is given from the ortho-Ps lifetime, $\tau_{3}$,

$$
\tau_{3}=0.5\left[1-\frac{R}{R_{0}}+\frac{1}{2 \pi} \sin \left(\frac{2 \pi R}{R_{0}}\right)\right]^{-1}
$$

In addition, the relative intensity corresponding to this lifetime, $\mathrm{I}_{3}$, contains information related to the number of the free-volume holes from which positronium annihilates. In this sense, combining the number $\left(\mathrm{I}_{3}\right)$ and size $\left(\tau_{3}\right)$ of free volume holes an estimation of the apparent free volume fraction $\left(\mathrm{f}_{\text {app }}\right)$ can be obtained (see for more details Refs [10]).

$$
f_{\text {app }}=V_{f} I_{3}
$$

DMA measurements, loss tangent (damping or internal friction), $\tan (\phi)$, and dynamic shear modulus, $\mathrm{G}$ ', were carried out as a function of temperature at frequencies close to $5 \mathrm{~Hz}$. Measurements were performed during heating with a heating rate of $1 \mathrm{~K} / \mathrm{min}$. The temperature range of the measurements was between 180 $\mathrm{K}$ and $380 \mathrm{~K}$. Measurements were performed under Argon atmosphere at atmospheric pressure. The samples for DMA studies were parallelepiped bars of around $5 \mathrm{~mm}$ width, $4 \mathrm{~mm}$ thick and $30 \mathrm{~mm}$ length. The maximum shear strain on the sample was $2 \times 10^{-4} \cdot \tan (\phi)$ values were independent of the amplitude of the oscillating strain, i. e. doubling the applied stress led to the doubling of the strain response [14]. The estimated uncertainties for $\tan (\phi)$ and $\mathrm{G}^{\prime}$ were less than $3 \%$ and $10 \%$, respectively.

\section{RESULTS AND DISCUSSION}

Figure 1 shows the $\tan (\phi)$ and $\mathrm{G}^{\prime}$ values measured at $300 \mathrm{~K}$, temperature which is near the maximum in damping corresponding to the melting of crystals in EPDM $[2,5,6]$. As it can be seen from the Figure, $\tan (\phi)$ values increase as the irradiation dose increases indicating that the volume fraction of crystallites increases as the doses increases [5,6].

The error bars for tan $(\phi)$ are around $10 \%$ due to the contribution of the damping background which increases the uncertainty of this value at an isolated temperature. Then, despite the non-monotonous behaviour of the measured points, an increase on the volume fraction of crystals as the dose increases can be proposed. The increase in the volume fraction of crystallites was already explained through a chemicrystallization process promoted by neutron impacts $[2,6,10,15,16]$. In fact, neutron irradiation produces chain scissions, the scission products having less restricted mobility. Disentanglement of such fragments allows them to crystallize into imperfect, low-melting point crystals, increasing the overall crystalline content $[2,6,10,15,16]$. In addition, the dynamic modulus exhibits an increase up to 415 Gy related to the development of new crystalline zones promoted by neutron impacts. However, the sample irradiated at 830 Gy exhibits smaller values of G' than the samples irradiated at $415 \mathrm{~Gy}$ and at $4150 \mathrm{~Gy}$. Sample irradiated at 8300 Gy shows the smallest values of G', among irradiated samples, due to the destruction of the polymer matrix promoted by neutron impacts at the highest dose used in this work [2,6].

In order to explain the behaviour of the dynamic modulus as a function of the irradiation dose, attention must be paid not only to the volume fraction of crystals, but also to the size of crystallites promoted by chemicrystallization. Figure 2 shows the behaviour of the hole free volume $\left(\mathrm{V}_{\mathrm{f}}\right)$, and the apparent fractional free volume, AFFV $\left(\mathrm{V}_{\mathrm{f}} \mathrm{x} \mathrm{I}_{3}\right)$, determined from PALS for the non-irradiated and irradiated samples as a function of irradiation dose. As it can be seen from the Figure, the AFFV increases monotonously as the 
irradiation dose increases due to the increase in the volume fraction of the crystalline zones promoted by neutron impacts through a chemicrystallization process. Indeed, chemicrystallization is produced by the piling up of nearby located cut polymer chains of the amorphous matrix. The length of the polymer chains per unit area, within the newly formed crystalline zone, is shorter than when the same zone is amorphous, leading to a less dense matrix. Therefore, the AFFV (empty space) increases with the increase in the volume fraction of the new crystallites [2,10,17].

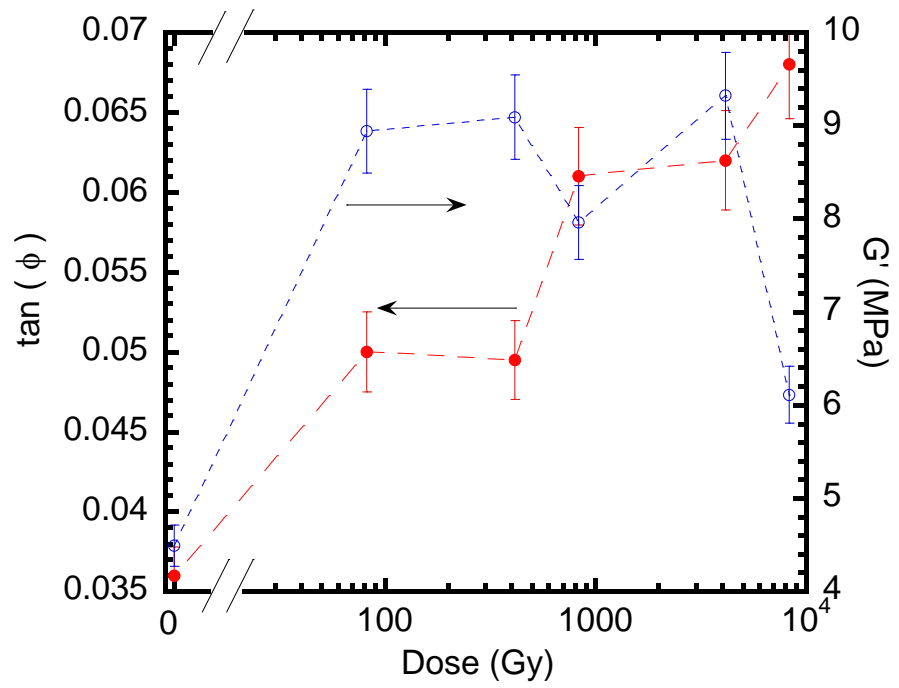

Figure 1: Damping $(\tan (\phi))$ and dynamic modulus $\left(\mathrm{G}^{\prime}\right)$ values measured at $300 \mathrm{~K}$ for the non-irradiated and irradiated samples as a function of irradiation dose.

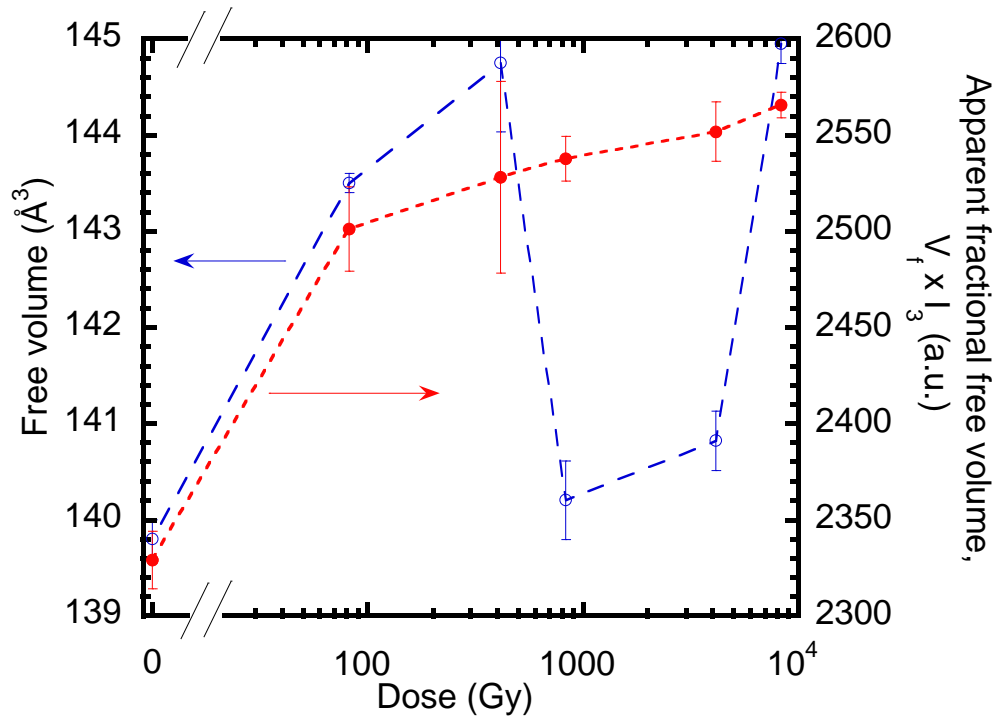

Figure 2: Hole free volume $\left(\mathrm{V}_{\mathrm{f}}\right)$, and the apparent fractional free volume (empty space), AFFV $\left(\mathrm{V}_{\mathrm{f}} \mathrm{x} \mathrm{I}_{3}\right)$, determined from PALS for the non-irradiated and irradiated samples as a function of irradiation dose.

The behaviour of the hole free-volume as a function of the irradiation dose is also shown in Figure 2. As the free volume from PALS measures the size of the holes into the polymer matrix we can deduce the following evolution according to dose: The size of hole increases up to an irradiation dose of $415 \mathrm{~Gy}$, and it decreases to a value close to the non-irradiated sample for an irradiation dose of $830 \mathrm{~Gy}$. Subsequently, for higher irradiation doses the free volume increases again, reaching its highest value for a dose of $8300 \mathrm{~Gy}$. In fact, recently, it was reported that the size of the holes into the polymer matrix is controlled by the size of the crystals. A larger size of the crystals leads to larger size in the hole free volume and vice-versa [9,10]. This correspondence is explained by means of the inclusion theory, when the inclusion is smaller than the size of 
the hole into the matrix $[9,10,18]$. Therefore, the jump-down of the modulus at 830 Gy can be related to the marked decrease in the size of crystals during the irradiation process. In fact, despite the volume fraction of crystals increases, at this dose, the decrease in the size of crystals leads to a decrease in the modulus of the rubber. On increasing the dose, even if the size of crystals has not been restored to the size at $415 \mathrm{~Gy}$, the further increase in the volume fraction of crystals leads to a new increase in the modulus. This effect can be understood through a parallel with the case of competition between volume fraction and size of particles in composite materials regarding the modulus value [18]. The modification of the size of crystallites was explained considering the competition of two physical effects during neutron irradiation: (i) the growing of the small crystals for decreasing the interface energy through a chemicrystallization process and (ii) the deterioration of crystals as a result of neutron irradiation [2,5,17].

Figure 3 shows the endothermic reaction related to the melting of crystalline zones for non-irradiated and irradiated samples at around $285 \mathrm{~K}$, after the base-line subtraction, where only some doses were included for clarity [19]. The melting temperature is in reasonable agreement with the data from Figure 1 and previous reported works $[2,6,10]$. The percentage of crystallinity was determined by considering the relation of the measured enthalpy to the melting enthalpy of crystallites in $100 \%$ crystalline polyethylene $(290 \mathrm{~J} / \mathrm{g})$ [19], see right axis in Figure 4. As it can be seen from the figure, the volume fraction increases up to 415 Gy and then decreases at 830 Gy. Subsequently, the volume fraction re-increases as the dose increases.

It is interesting to note that the volume fraction of crystallites determined from DSC exhibits a small value for the sample irradiated at $830 \mathrm{~Gy}$. In contrast, the volume fraction obtained from DMA and PALS do not reveal this decrease on it. However, both DMA and PALS, reveal a decrease in the values of the modulus and in the size of crystals, respectively. The value of the volume fraction, which is determined from DSC for first time in these samples, could be masked in DMA studies since the value of $\tan (\phi)$ was considered without the subtraction of the damping background; as said before. The subtraction of the damping background cannot be done yet, due to the overlapping of several relaxation processes in this temperature range $[2,5,6,10]$. In addition, from PALS, the chain scission process which takes place during irradiation could influence the amount of empty space in the sample giving rise also to small discrepancies. Besides, the crystalline volume fraction determined from IR exhibits some deviations with results from DMA and DSC. It could be related to some problem in determining the background damping, the base-line and the normalized curve in DMA, DSC and IR studies, respectively. Nevertheless, the whole trends measured by means of each used technique are in reasonable agreement each others.

Similarly as it occurs in polypropylene based-composites [20,21,22], the reinforcement with Bayerite could take some effect both on the crystallinity degree reached from the fabrication process and also on the activation parameters of the glass transition and the melting of crystalline zones. However, as the weight fraction of $44 \%$ of Bayerite is always the same for electrical requirements, it does not represent a variable in the present study.

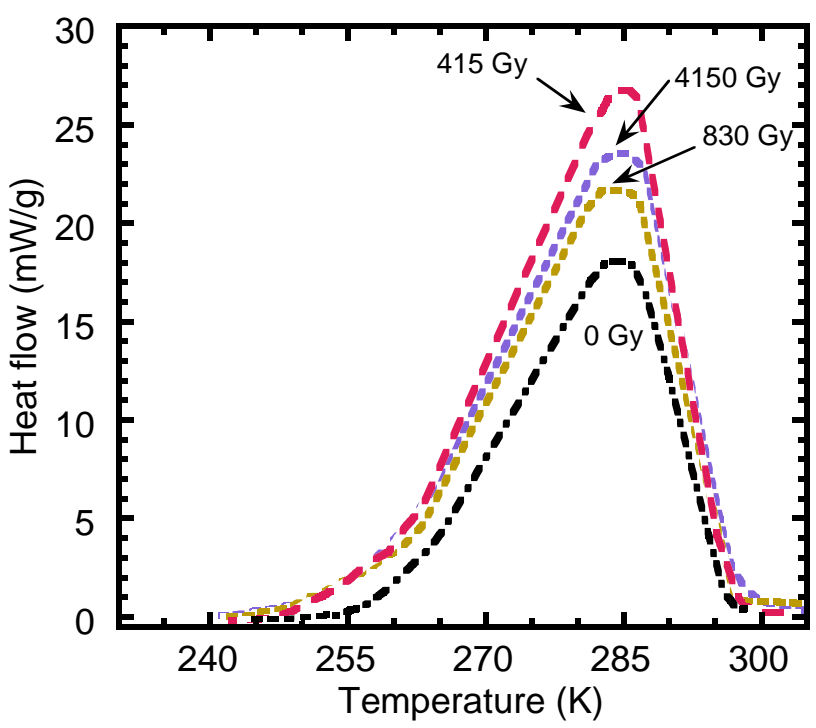

Figure 3: Endothermic reaction from DSC for non-irradiated and some irradiated samples. Labels in the curves mean the dose in Gy. 


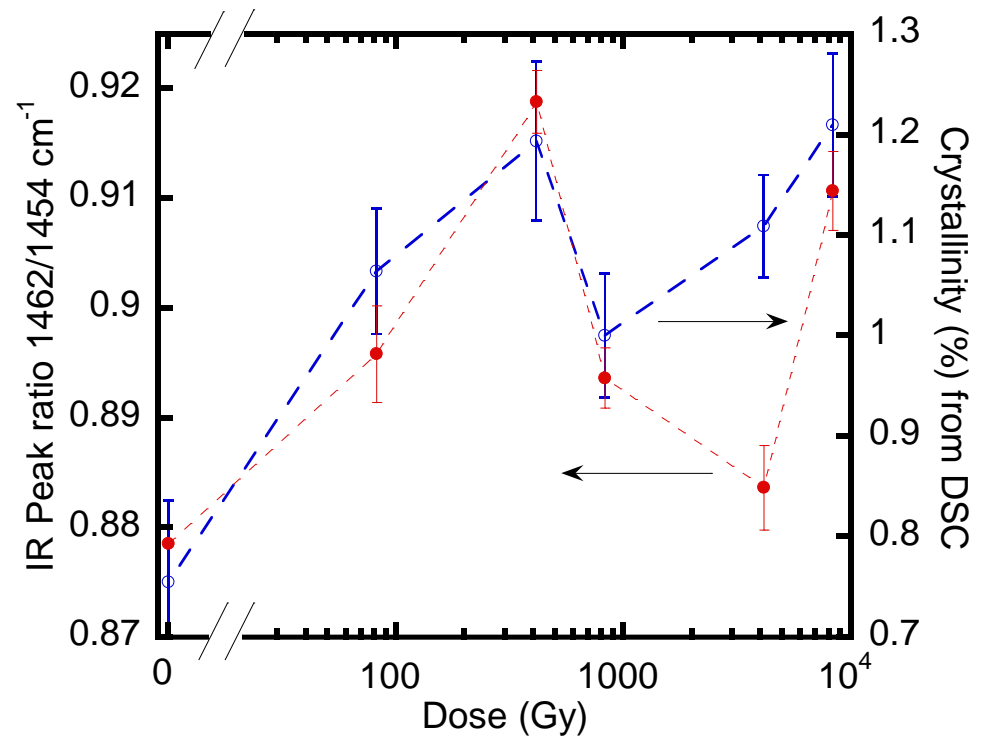

Figure 4: Left axis: Ratio between the absorbance intensities (IR) at $1462 \mathrm{~cm}^{-1}$ and $1454 \mathrm{~cm}^{-1}$. Right axis: Volume fraction of crystals determined from DSC.

Regarding the additional irradiation contribution to the matrix with $\beta$ particles, these doses are much smaller than the corresponding to the neutrons. In addition, irradiation with gamma photons at doses around the double than the attained by $\beta$ particles does not give rise to changes in the crystallinity degree [6]. Moreover, the neutrons can penetrate into the sample and the atom without hindrance. When they collide with nuclei they are either, absorbed by them or recoil from them. In elastic neutron scattering in substances containing a large number of hydrogen atoms, the energy of incident neutrons is halved on an average, being transferred partially to recoil protons $[23,24]$. Then, the damage of EPDM promoted by neutron irradiation can be considered as the main effect.

The commercial EPDM used as housing of non-ceramic electrical insulators is crosslinked, giving rise to a semi-crystalline rubber $[25,26]$. Therefore, the volume fraction of crystallites is small and then the effects of changes in crystallinity should be related to changes in the whole polymer matrix and not only to changes occurring at the polymeric interface between Bayerite particles and the rubber.

In another light, changes in the structure and thermal response in the Bayerite promoted either from neutron irradiation or from the deterioration of the polymeric matrix during irradiation cannot be detected from X-ray diffraction and differential thermal analysis studies [2].

The IR spectra for non-irradiated and irradiated samples show the characteristic peaks for the EPDM at $2918 \mathrm{~cm}^{-1}$ corresponding to the saturated hydrocarbon backbone of aliphatic alkyl symmetric/asymmetric $\mathrm{C}-\mathrm{H}$ stretching vibration. The peaks at $1465 \mathrm{~cm}^{-1}$ and $1380 \mathrm{~cm}^{-1}$ are assigned to $-\mathrm{CH}_{2}$ scissoring vibrations and $\mathrm{C}-\mathrm{H}$ bending vibrations of $-\mathrm{CH}_{3}$ from the propylene unit, respectively. In addition, the peaks related to the ATH filler were also recorded within the wavenumber regions $3300 \mathrm{~cm}^{-1}-3600 \mathrm{~cm}^{-1}$ and $900 \mathrm{~cm}^{-1}-$ $1020 \mathrm{~cm}^{-1}$. For wavenumbers, smaller than $900 \mathrm{~cm}^{-1}$ the overlapping of signals from the diene and other components of the EPDM occur. In order to highlight the differences among the IR spectra for non-irradiated and irradiated samples, the doses where the maximum volume fraction of crystallites occur, are plotted in Figure 5.

From IR spectra, the crystallinity in polyethylene can be estimated from the ratio between the absorbances which appear at $731 \mathrm{~cm}^{-1}$ and $719 \mathrm{~cm}^{-1}$, which correspond to the flexion of methylenes $-\mathrm{CH}_{2}-$ bending and rocking, respectively [27]. However, in the case of the EPDM these peaks are overlapped with several signals from the constituents of EPDM, forbidding the determination of the crystallinity degree (see Figure 5). 


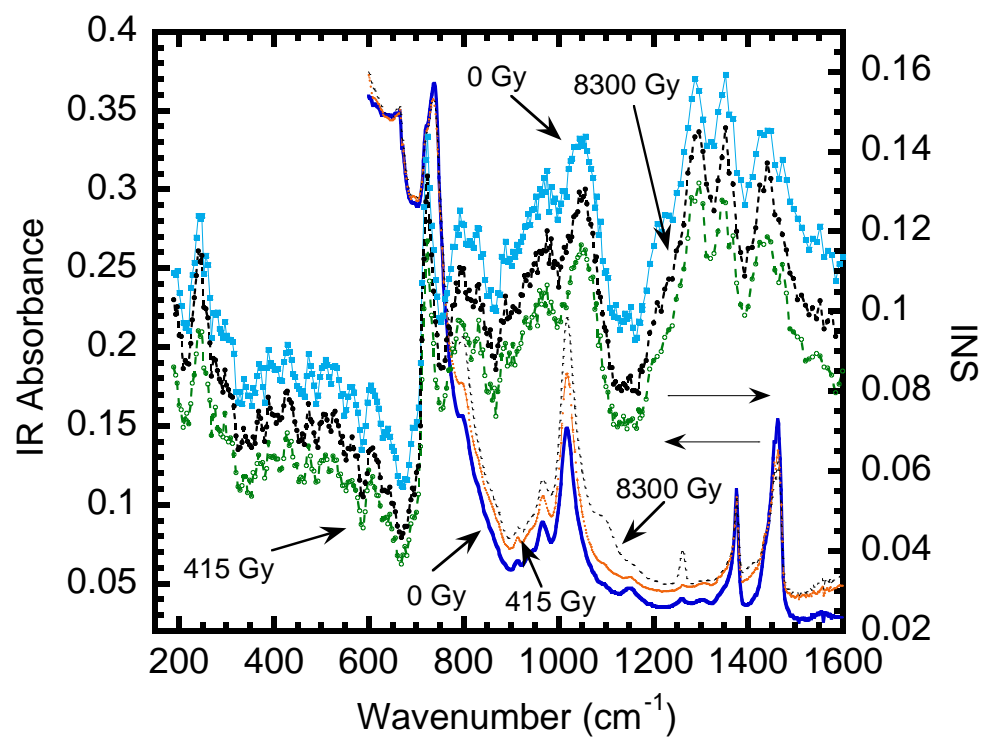

Figure 5: Left axis: IR spectra (lines) for non-irradiated and irradiated sample. Right axis: INS spectra (circles) for nonirradiated and irradiated samples.

Therefore, INS studies were carried out in order to attempt to determine the crystallinity changes in EPDM. In fact, as some peaks in the INS spectrum are not seen in the infrared or Raman spectra: for example the factor group splitting of all the modes in the INS is readily apparent because of the absence of selection rules. In the infrared and Raman spectra, some of the factor group components are either forbidden or have zero intensity [28]. In addition, the access to the low energy region $\left(<300 \mathrm{~cm}^{-1}\right)$ is the usual situation in INS spectroscopy. For infrared and, to a lesser extent, Raman spectroscopy, this is not the case and for instrumental reasons, $200-400 \mathrm{~cm}^{-1}$ is the usual cut-off. Even when the region can be observed, it is often found that at least some of the vibrational and translational modes are very weak in an infrared or Raman spectrum [28]. Figure 5 shows the INS spectra for the non-irradiated sample and only for the samples irradiated at $415 \mathrm{~Gy}$ and $8300 \mathrm{~Gy}$, where the maximum volume fraction of crystallites occur, for the sake of clarity. As it can be seen from the Figure, clear differences cannot be distinguished among the spectra, even at the region of energies smaller than $600 \mathrm{~cm}^{-1}$. However, the vibrational spectra from INS for non-irradiated and irradiated samples exhibit different intensities (see Figure 5), From the whole studied samples a clear trend could not be established. Moreover, the curve with smallest intensity corresponds to the sample with the largest volume fraction of crystals, so it could be in disagreement [28]. Then, more effort is needed for resolving the crystallinity evolution in neutron irradiated commercial EPDM for electrical applications from INS studies.

Nevertheless, another chance to obtain the degree of crystallinity, taking in consideration the degree of the amorphous component of the polyethylene, could be possible [29]. In fact, by comparing the signals at $1474 \mathrm{~cm}^{-1}$ and $1464 \mathrm{~cm}^{-1}$ it could be done. The peaks at $1474 \mathrm{~cm}^{-1}$ and $731 \mathrm{~cm}^{-1}$ are only related to the crystalline phase. In contrast, the peaks at $1464 \mathrm{~cm}^{-1}$ and $719 \mathrm{~cm}^{-1}$ are promoted by the amorphous phase. In irradiated EPDM were recorded two peaks which are close between them, at $1462 \mathrm{~cm}^{-1}$ and $1454 \mathrm{~cm}^{-1}$, see Figure 6. In order to compare the spectra among non-irradiated and irradiated samples, spectra were normalized to peak at $2918 \mathrm{~cm}^{-1}$. Therefore, a straightforward analysis allows us to relate the peak at 1462 $\mathrm{cm}^{-1}$ to the contribution from the amorphous phases, while the peak at $1454 \mathrm{~cm}^{-1}$ can be related to the contribution from the crystalline phase. In fact, Figure 4 shows the ratio of these two intensities for nonirradiated and irradiated samples (see left axis).

It should be stressed that, the behaviour of the volume fraction of crystallites as a function of irradiation dose in EPDM, determined from IR results in reasonable agreement with the above results. In contrast, from a detailed analysis of INS spectra within the zone $1100 \mathrm{~cm}^{-1}-1700 \mathrm{~cm}^{-1}$, the behavior of the ratio for the $1462 \mathrm{~cm}^{-1}$ and $1454 \mathrm{~cm}^{-1}$ peaks cannot be related to the crystallinity evolution viewed from PALS, DSC, IR and DMA studies. 


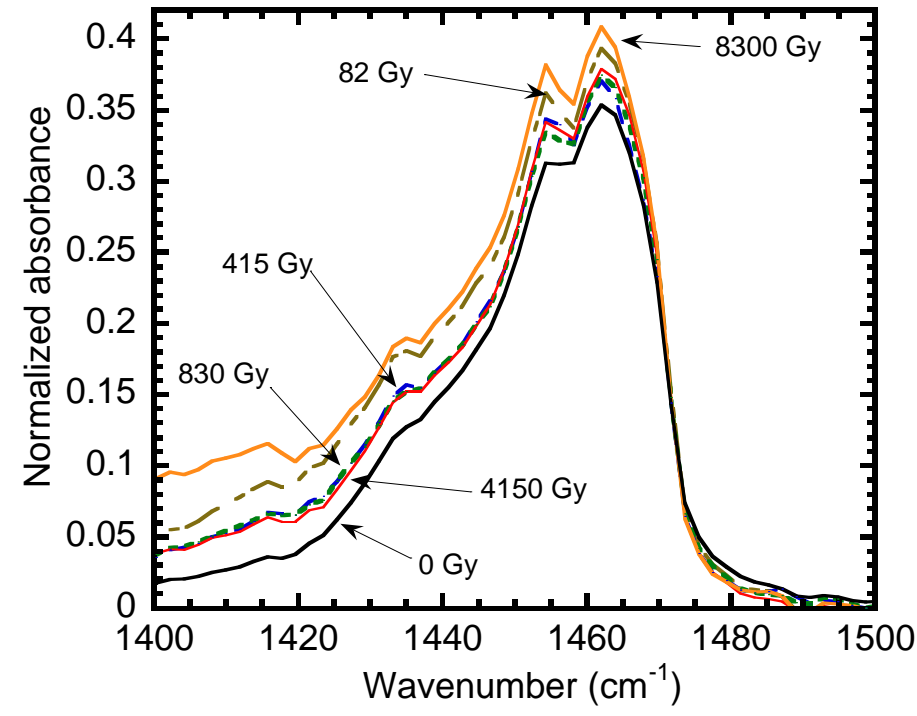

Figure 6: Magnification zone of IR spectra close to $1440 \mathrm{~cm}^{-1}$ for non-irradiated and irradiated samples.

\section{CONCLUSIONS}

Inelastic neutron scattering studies, as performed in the present work, were not appropriate for determining the changes in the crystallinity degree in neutron irradiated commercial EPDM. Therefore, more effort is needed for resolving the crystallinity evolution in neutron irradiated commercial EPDM for electrical applications from inelastic neutron scattering studies. In contrast, infrared absorption spectroscopy has been applied successfully to determine the behaviour of crystallinity in neutron irradiated commercial EPDM. The ratio between the intensities of the peaks at $1462 \mathrm{~cm}^{-1}$ and $1454 \mathrm{~cm}^{-1}$ was considered. Differential scanning calorimetry studies corroborate the behaviour of the volume fraction of crystalline zones in neutron irradiated EPDM obtained from infrared spectroscopy experiments. The results from dynamic mechanical analysis and positron annihilation spectroscopy, which give also information about the size of crystallites, were also in agreement with infrared spectroscopy and differential scanning calorimetry results. The volume fraction and size of crystallites increases as the dose increases up to $415 \mathrm{~Gy}$. At $830 \mathrm{~Gy}$, a decrease both in the volume fraction and size of crystals has been determined. For higher doses the volume fraction and size of crystals re-increase.

\section{ACKNOWLEDGMENTS}

The Institute Laue Langeving (ILL) - IN1-Lagrange facility is acknowledged for the allocated neutron beam time (Exp. 9-11-1635). This work was partially supported by the CONICET-PIP No. 179CO, the PID-UNR ING 450 (2014-2017), the Cooperation Agreement between the Universidad del País Vasco/Euskal Herriko Unibertsitatea and the Universidad Nacional de Rosario, Res 3243/2015 and the Cooperation Agreement between the Universidad Pública de Navarra and the Universidad Nacional de Rosario, Res. 3247/2015. A.O.L wishes to say thanks to his friend the Rev. P. Ignacio Peries for everything.

\section{BIBLIOGRAPHY}

[1] HACKAM, R., “Outdoor HV Composite Polymeric Insulators”, IEEE, Transactions on Dielectrics and Electrical Insulation, v. 6, n. 5, pp. 557-585, 1999.

[2] LAMBRI, O.A., TARDITTI, F., CANO, J.A., ZELADA, G.I., et al., "Influence of the Empty Space and the Internal Stresses on the Dielectric Strength in Two-Phase Polymer", IEEE, Transactions on Dielectrics and Electrical Insulation, v. 20, n. 5, pp. 1869 - 1881, 2013.

[3] SORICHETTI, P.A., MATTEO, C.L., LAMBRI, O.A., et al., "Structural changes in EPDM subjected to ageing in high voltage transmission lines", IEEE, Transactions on Dielectrics and Electrical Insulation, v. 14, n. 5, pp. 1170-1182, 2007.

[4] CELINA, M., GILLEN, K.T., WISE, J., et al., "Anomalous aging phenomena in a crosslinked polyolefin cable insulation”, Radiation Physics and Chemistry, v. 48, n. 5, pp. 613-626, 1996. 
[5] SALVATIERRA, L.M., LAMBRI, O.A., MATTEO, C.L., et al., "Growing of crystalline zones in EPDM irradiated with a low neutron flux", Nuclear Instruments and Methods in Physics Research Section B: Beam Interactions with Materials and Atoms, v. 225, n. 3, pp. 297-304, 2004.

[6] LAMBRI, O.A., SALVATIERRA, L.M., SÁNCHEZ, F.A., et al., "Crystal growth in EPDM by chemicrystallisation as a function of the neutron irradiation dose and flux level", Nuclear Instruments and Methods in Physics Research Section B: Beam Interactions with Materials and Atoms, v. 237, n. 3, pp. 550$562,2005$.

[7] CULLITY, B.D., Elements of X-ray Diffraction, Reading, Addison-Wesley Publishing Co., 1967.

[8] BARUCHEL, J., HODEAU, J.L., LEHMANN, M.S., et al., Neutron and Synchrotron Radiation for Condensed Matter Studies, Berlin, Springer-Verlag, Les Editions de Physique, 1994.

[9] MOCELLINI, R.R., LAMBRI, O.A., MATTEO, C.L., et al., "Elastic misfit in two-phase polymer", Polymer, v. 50, n. 19, pp. 4696-4705, 2009.

[10] LAMBRI, O.A., PLAZAOLA, F., AXPE, E., MOCELLINI, R.R., et al., "Modification of the mesoscopic structure in neutron irradiated EPDM viewed through positron annihilation spectroscopy and dynamic mechanical analysis", Nuclear Instruments and Methods in Physics Research Section B: Beam Interactions with Materials and Atoms, v. 269, n.3, pp. 336-344, 2011.

[11] ASTM Standard D3900-05a, "Rubber-Determination of Ethylene Units in Ethylene-Propylene Copolymers (EPM) and in Ethylene-Propylene-Diene Terpolymers (EPDM) by Infrared Spectrometry", ASTM International, West Conshohocken, PA, 2005.

[12] BAARD, J.H., ZIJP, W.L., NOLTHENIUS, H.J., Nuclear Data Guide for Reactor Neutron Metrology, Springer Netherlands, 1989.

[13] KANSY, J., "Microcomputer program for analysis of positron annihilation lifetime spectra", Nuclear Instruments and Methods in Physics Research Section A: Accelerators, Spectrometers, Detectors and Associated Equipment, v. 374, n. 2, pp. 235-244, 1996.

[14] LAMBRI, O.A. "A review on the problem of measuring nonlinear damping and the obtainment of intrinsic damping”, In: Martinez-Mardones, J., Walgraef, D., Wörner, C.H. (eds.). Materials Instabilities. New York, USA, World Scientific Publishing Co Pte Ltd, 2000.

[15] CHARLESBY, A., Atomic radiation and polymers, Oxford, Pergamon Press, 1960.

[16] CHARLESBY, A., CALLAGHAN, L., "Crystallinity changes in irradiated polyethylenes", Journal of Physics and Chemistry of Solids, v. 4, n. 4, pp. 306-314, 1958.

[17] LAMBRI, O.A., MATTEO, C.L., MOCELLINI, R.R., et al., Propiedades Viscoelásticas y Eléctricas de Sólidos y Líquidos - Una introducción a la Electro-Reología con sus aplicaciones tecnológicas, 1st edition, Rosario, UNR Editora, 2008.

[18] MURA, T. Micromechanics of defects in solids, New York, USA, Martinus Nijhoff Publishers, 1987.

[19] BONIFACICH, F.G., GIORDANO, E.D.V., LAMBRI, O.A., et al., "Study of the dielectric in EPDM by non destructive dynamic mechanical analysis experiments conducted under high electric field," IEEE,

Transactions on Dielectrics and Electrical Insulation. In press 2017

[20] WEIDENFELLER, B., RIEHEMANN, W., LEI, Q., "Mechanical spectroscopy of polymer magnetite composites”, Material Science Engineering A, v. 370, pp. 278-283, 2004.

[21] WEIDENFELLER, B., "Internal friction studies of particulate filled polypropylene", Material Science Engineering A., v. 442, pp. 371-374, 2006.

[22] MOCELliNI, R.R., LAMBRI, O.A., GARGICEVICH, D., et al., "Magnetic memory effect in magnetite charged polypropylene composite", Composite Interfaces, v. 24, pp. 611-613, 2017.

[23] YARMONENKO, S. P., Radiobiology, Moscow, MIR Publishers, 1988.

[24] SPROUlL, R. L., PHILlIPS, W. A., Modern Physics: The Quantum Physics of Atoms, Solids and Nuclei, John Wiley \& Sons, New York, 1980.

[25] WARD, I. M., SWEENEY, J., Mechanical Properties of Solid Polymers. Chichester, West Sussex, John Wiley \& Sons, Ltd, , 2012.

[26] MARK, J., NGAI, K., GRAESSLEY, W., MANDELKERN, L., et al., Physical Properties of Polymers. 3rd Edition. Cambridge, Cambridge University Press, 2004.

[27] ABU-ISA, I., "Thermal degradation of thin films of isotactic polypropylene and polypropylene with ketonic additives", Journal of Polymer Science Part A - 1: Polymer Chemistry, v. 8, n. 4, pp. 961-972, 1970. 
[28] MITCHELL, P.C.H., PARKER, S.F., RAMIREZ-CUESTA, A.J., et al., Vibrational spectroscopy with neutrons: with applications in chemistry, biology, materials science and catalysis. New York, New Jersey, World Scientific, 2005.

[29] URBAN, M.W., Attenuated total reflectance spectroscopy of polymers: theory and practice, Washington, American Chemical Society, 1996. 